\title{
Comparison of pulmonary function in patients with COPD, asthma-COPD overlap syndrome, and asthma with airflow limitation
}

This article was published in the following Dove Press journal:

International Journal of COPD

9 May 2016

Number of times this article has been viewed

\section{Yoshiaki Kitaguchi \\ Masanori Yasuo \\ Masayuki Hanaoka}

First Department of Internal Medicine, Shinshu University School of Medicine, Matsumoto, Japan
Correspondence: Masanori Yasuo First Department of Internal Medicine, Shinshu University School of Medicine, 3-I-I Asahi, Matsumoto 390-862I, Japan Email yasumasa@shinshu-u.ac.jp
Background: This study was conducted in order to investigate the differences in the respiratory physiology of patients with chronic obstructive pulmonary disease (COPD), asthma-COPD overlap syndrome (ACOS), and asthma with airflow limitation (asthma $\mathrm{FL}^{+}$).

Methods: The medical records for a series of all stable patients with persistent airflow limitation due to COPD, ACOS, or asthma were retrospectively reviewed and divided into the COPD group ( $\mathrm{n}=118)$, the ACOS group $(\mathrm{n}=32)$, and the asthma $\mathrm{FL}^{+}$group $(\mathrm{n}=27)$. All the patients underwent chest high-resolution computed tomography (HRCT) and pulmonary function tests, including respiratory impedance.

Results: The low attenuation area score on chest HRCT was significantly higher in the COPD group than in the ACOS group $(9.52 \pm 0.76$ vs $5.09 \pm 1.16, P<0.01)$. The prevalence of bronchial wall thickening on chest HRCT was significantly higher in the asthma $\mathrm{FL}^{+}$group than in the COPD group $(55.6 \%$ vs $25.0 \%, P<0.01)$. In pulmonary function, forced expiratory volume in 1 second $\left(\mathrm{FEV}_{1}\right)$ and peak expiratory flow rate were significantly higher in the asthma $\mathrm{FL}^{+}$group than in the ACOS group $(76.28 \% \pm 2.54 \%$ predicted vs $63.43 \% \pm 3.22 \%$ predicted, $P<0.05$ and $74.40 \% \pm 3.16 \%$ predicted vs $61.08 \% \pm 3.54 \%$ predicted, $P<0.05$, respectively). Although residual volume was significantly lower in the asthma $\mathrm{FL}^{+}$group than in the COPD group $(112.05 \% \pm 4.34 \%$ predicted vs $137.38 \% \pm 3.43 \%$ predicted, $P<0.01)$ and the ACOS group $(112.05 \% \pm 4.34 \%$ predicted vs $148.46 \% \pm 6.25 \%$ predicted, $P<0.01$ ), there were no significant differences in functional residual capacity or total lung capacity. The increase in $\mathrm{FEV}_{1}$ in response to short-acting $\beta_{2}$-agonists was significantly greater in the ACOS group than in the COPD group $(229 \pm 29 \mathrm{~mL}$ vs $72 \pm 10 \mathrm{~mL}, P<0.01)$ and the asthma $\mathrm{FL}^{+}$group $(229 \pm 29 \mathrm{~mL}$ vs $153 \pm 21 \mathrm{~mL}, P<0.05)$. Regarding respiratory impedance, resistance at $5 \mathrm{~Hz}$ and resistance at $20 \mathrm{~Hz}$, which are oscillatory parameters of respiratory resistance, were significantly higher in the asthma $\mathrm{FL}^{+}$group than in the COPD group at the whole-breath $\left(4.29 \pm 0.30 \mathrm{cmH}_{2} \mathrm{O} / \mathrm{L} / \mathrm{s}\right.$ vs $3.41 \pm 0.14 \mathrm{cmH}_{2} \mathrm{O} / \mathrm{L} / \mathrm{s}, P<0.01$ and $3.50 \pm 0.24 \mathrm{cmH}_{2} \mathrm{O} / \mathrm{L} / \mathrm{s}$ vs $2.68 \pm 0.10 \mathrm{cmH}_{2} \mathrm{O} / \mathrm{L} / \mathrm{s}, P<0.01$, respectively), expiratory, and inspiratory phases.

Conclusion: Although persistent airflow limitation occurs in patients with COPD, ACOS, and asthma $\mathrm{FL}^{+}$, they may have distinct characteristics of the respiratory physiology and different responsiveness to bronchodilators.

Keywords: ACOS, FOT, respiratory impedance, MostGraph

\section{Introduction}

Chronic obstructive pulmonary disease (COPD) is characterized by persistent airflow limitation that is usually progressive according to the Global initiative for chronic Obstructive Lung Disease (GOLD) guidelines. ${ }^{1}$ Spirometric criterion for airflow 
limitation is forced expiratory volume in 1 second $\left(\mathrm{FEV}_{1}\right)$ / forced vital capacity (FVC) ratio less than 70\% after inhalation of bronchodilators, according to the GOLD guidelines. ${ }^{1}$ However, COPD is not the only disease that shows persistent airflow limitation. Asthma is characterized by chronic inflammation and airway remodeling and may also cause persistent airflow limitation, ${ }^{2}$ although the patterns of inflammation, the affected structures, and the prime anatomic site at which pathological changes occur are different. ${ }^{3}$ In the clinical setting, asthma and COPD are among the most commonly encountered chronic lung diseases. ${ }^{1,4}$ Asthma may be a risk factor for the development of COPD. ${ }^{5}$ It may therefore be problematic to differentiate asthma from COPD, especially in older patients. It is difficult to clinically differentiate between COPD and asthma in some patients with persistent airflow limitation. ${ }^{6}$ Moreover, COPD and asthma may overlap and converge in older individuals. ${ }^{7,8}$ There is increasing clinical recognition of the coexistence of COPD and asthma in individual patients, which results in a clinical syndrome known as asthma-COPD overlap syndrome (ACOS). ${ }^{9-13}$

The forced oscillation technique (FOT) is a simple method for assessing the oscillatory flow resistance of the respiratory system and has provided important findings in respiratory physiology. ${ }^{14-16}$ Previous studies have revealed that several parameters evaluated using the FOT may be useful for discriminating between patients with COPD and asthma. ${ }^{17,18}$ However, there continues to be a lack of information on the differences in pulmonary function, including respiratory impedance, among patients with COPD, ACOS, and asthma with airflow limitation (asthma $\mathrm{FL}^{+}$). This retrospective study was conducted in order to investigate the differences in the respiratory physiology of patients with these chronic obstructive diseases. The aim of the study was to clarify the characteristics of pulmonary functions, including pulmonary impedance, and the findings of chest high-resolution computed tomography (HRCT) of patients with COPD, ACOS, and asthma $\mathrm{FL}^{+}$, and these findings may therefore play a role in developing the diagnostic criteria of ACOS.

\section{Methods}

\section{Patients}

The medical records for a series of all stable patients with persistent airflow limitation due to COPD, ACOS, or asthma, who were seen at the outpatient clinic of Shinshu University Hospital from April 2011 to October 2015, were retrospectively reviewed to obtain the patients' clinical data, including the diagnosis, age, sex, body weight, body height, smoking history, laboratory data, and imaging data. All the patients underwent chest HRCT and pulmonary function tests, including respiratory impedance.

The diagnosis of COPD was based on the patients' clinical history and symptoms, including dyspnea on exertion and pulmonary function characterized by persistent airflow limitation $\left(\mathrm{FEV}_{1} / \mathrm{FVC}<70 \%\right.$ after inhalation of short-acting $\beta_{2}$-agonists) in accordance with the GOLD guidelines. ${ }^{1}$ The patients with COPD who had no history of asthma or asthmatic symptoms were categorized into the COPD group ( $\mathrm{n}=118)$. The patients with COPD who had experienced asthmatic symptoms, such as episodic breathlessness, wheezing, cough, and chest tightness worsening at night or in the early morning, were categorized into the ACOS group $(n=32)$, in accordance with GOLD ${ }^{1}$ and Global Initiative for Asthma (GINA) guidelines ${ }^{4,13}$ as previously reported. ${ }^{19}$ All the patients with ACOS had a smoking history of $>20$ packyears. The diagnosis of asthma was based on the clinical history and symptoms in accordance with GINA. ${ }^{4}$ Patients with asthma who showed persistent airflow limitation $\left(\mathrm{FEV}_{1} /\right.$ FVC $<70 \%$ after inhalation of short-acting $\beta_{2}$-agonists) were categorized into the asthma $\mathrm{FL}^{+}$group $(\mathrm{n}=27)$.

A total of 243 patients were included in the initial analysis. Of them, 66 patients were excluded in the final analysis because they had a coexistent diagnosis of other respiratory diseases, such as pulmonary fibrosis (26 patients) or bronchiectasis (two patients) or they did not undergo the FOT measurements (14 patients) or chest HRCT (24 patients). No patient had a respiratory tract infection or an exacerbation of COPD and/or asthma during the preceding 3 months.

This study was approved by the institutional research ethics committee of Shinshu University School of Medicine, and all patients gave their written informed consent to participate.

\section{Pulmonary function tests}

Spirometry, measurements of the diffusion capacity of the lung for carbon monoxide (DLco) and closing volume, and a global measure of ventilation heterogeneity (the slope of Phase III of the single breath nitrogen washout test [delta $\mathrm{N}_{2}$ ]) were performed using a pulmonary function testing system (Chestac-8800; Chest Co., Ltd., Tokyo, Japan). FEV 1 was measured before and 20 minutes after inhalation of shortacting $\beta_{2}$-agonists ( $20 \mu \mathrm{g}$ of procaterol hydrochloride) by aerosol (metered-dose inhaler) with a spacer to evaluate the reversibility of airflow limitation. The functional residual capacity was measured using a body plethysmograph (Body Box; MGC Diagnostics, Ann Arbor, MI, USA), after which the patients immediately inspired to total lung capacity (TLC) 
and expired maximally to residual volume (RV). The local Japanese reference data, ${ }^{20}$ developed by the Japanese Respiratory Society, were used to derive the predicted values for $\mathrm{FEV}_{1}$ and vital capacity, while the predicted values for DLco, DLco/alveolar volume, and lung volumes (RV and TLC) measured using the body plethysmograph were determined using the formulas described by Nishida et $\mathrm{al}^{21}$ and Boren et al, ${ }^{22}$ respectively. Some patients used short-acting $\beta_{2}$-agonists as needed to relieve dyspnea but did not use them on the day the pulmonary function tests were performed.

Respiratory impedance was measured using a commercially available multifrequency FOT device (MostGraph- $01^{\circledR}$ ) as previously reported, ${ }^{17,23,24}$ following the standard recommendations. ${ }^{25} \mathrm{We}$ evaluated the resistance at $5 \mathrm{~Hz}$ (R5), resistance at $20 \mathrm{~Hz}(\mathrm{R} 20)$, reactance at $5 \mathrm{~Hz}$ (X5), resonant frequency (Fres), and low-frequency reactance area (ALX). The oscillatory parameters were expressed at whole-breath, inspiratory, and expiratory phases. The difference between the inspiratory and expiratory phases was calculated for each oscillatory parameter. These FOT measurements were performed prior to the other pulmonary function tests.

The pulmonary function tests were performed by two special technicians according to the American Thoracic Society criteria. Two or three tests were repeated to guarantee repeatability.

\section{Evaluation of the degree of emphysema and bronchial wall thickening}

Emphysema was evaluated by HRCT according to the method reported previously. ${ }^{26,27}$ Briefly, HRCT findings were evaluated at three anatomical levels at full inspiration; near the superior margin of the aortic arch, at the level of the carina, and at the level of the orifice of the inferior pulmonary veins. The low attenuation area (LAA) was visually scored in each bilateral lung field according to the method of Goddard et al..$^{28}$ Total scores were calculated, and the severity of emphysema was graded as follows: score 0 , LAA $<5 \%$; score $1,5 \% \leq$ LAA $<25 \%$; score $2,25 \% \leq$ LAA $<50 \%$; score $3,50 \% \leq$ LAA $<75 \%$; and score $4,75 \% \leq$ LAA. Thus, the total emphysema scores ranged from 0 to 24. Bronchial wall thickening (BWT) in all lung fields was graded visually as reported previously: ${ }^{26,27}$ grade 0 , none; grade $1,<50 \%$ adjacent pulmonary artery diameter; and grade $2, \geq 50 \%$ adjacent pulmonary artery diameter. The patients without BWT showed BWT of grade 0 , and patients with BWT showed BWT of grade 1 or more. HRCT images were independently analyzed by two pulmonologists with no knowledge of the patients' clinical status.

\section{Statistical analysis}

The values shown in the text, figures, and tables represent mean \pm standard error of the mean. The data distribution of the variables in various groups was first assessed using Bartlett's test. When the data for the variables showed a normal distribution, they were compared using one-way analysis of variance, followed by multiple comparisons according to the Tukey-Kramer method. When the data for the variables did not show a normal distribution, the variables were compared using the Kruskal-Wallis test, followed by multiple comparisons among groups with the nonparametric TukeyKramer method. All statistical analyses were performed using Windows-compatible software (StatFlex Version 6.0; Artech, Osaka, Japan). $P$-values of less than 0.05 were considered to indicate statistical significance in all of the statistical analyses.

\section{Results}

\section{Clinical characteristics of each group}

Table 1 shows the age, sex, body mass index, Brinkman index, peripheral eosinophil count, and chest HRCT findings of each group. The proportion of females was significantly higher in the asthma $\mathrm{FL}^{+}$group than in the other groups. The Brinkman index and LAA score were significantly lower in the asthma $\mathrm{FL}^{+}$group than in the other groups. Although there were no significant differences in the peripheral eosinophil count among the three groups, it tended to be higher in the ACOS and asthma $\mathrm{FL}^{+}$groups than in the COPD group. There were significant differences in the LAA score on chest HRCT among the three groups, and the LAA score was significantly higher in the COPD group than in the ACOS group. The prevalence of BWT on chest HRCT was significantly higher in the asthma $\mathrm{FL}^{+}$group than in the COPD group.

\section{Pulmonary function tests}

$\mathrm{FEV}_{1}$ and peak expiratory flow rate were significantly higher in the asthma $\mathrm{FL}^{+}$group than in the ACOS group (Table 2). $\mathrm{RV}$ was significantly lower in the asthma $\mathrm{FL}^{+}$group than in the other groups, although there were no significant differences in functional residual capacity and TLC. DLco and DLco/alveolar volume were significantly higher in the asthma $\mathrm{FL}^{+}$group than in the other groups. There were no significant differences in delta $\mathrm{N}_{2}$ and closing volume/vital capacity among the three groups.

Figure 1 shows the reversibility of airflow limitation in response to short-acting $\beta_{2}$-agonists, which was expressed by an increase in $\mathrm{FEV}_{1}$ from the baseline value. The increase in $\mathrm{FEV}_{1}$ was significantly greater in the ACOS group than 
Table I Clinical characteristics of patients with COPD, ACOS, and asthma $\mathrm{FL}^{+}$

\begin{tabular}{|c|c|c|c|}
\hline & COPD $(n=|| 8)$ & $A \cos (n=32)$ & Asthma $\mathrm{FL}^{+}(\mathrm{n}=27)$ \\
\hline Age, years & $71.9 \pm 0.8$ & $69.1 \pm 1.2$ & $70.3 \pm 2.2$ \\
\hline \multicolumn{4}{|l|}{ Sex } \\
\hline Male, $n(\%)$ & $96(88.9)$ & $30(93.8)$ & II $(40.7)^{* * * *}$ \\
\hline Female, $\mathrm{n}(\%)$ & $12(11.1)$ & $2(6.3)$ & $16(59.3)^{* * * *}$ \\
\hline Body mass index, $\mathrm{kg} / \mathrm{m}^{2}$ & $22.4 \pm 0.3$ & $23.1 \pm 0.6$ & $22.4 \pm 0.4$ \\
\hline Brinkman index, pack-years & $51.88 \pm 2.88$ & $47.47 \pm 6.02$ & $2.39 \pm 1.11 * * *$ \\
\hline Peripheral eosinophil count, \% & $2.77 \pm 0.20$ & $3.66 \pm 0.52$ & $3.82 \pm 0.69$ \\
\hline Peripheral eosinophil count, $\mathrm{mm}^{3}$ & $168.12 \pm 11.53$ & $232.96 \pm 40.04$ & $227.7 I \pm 46.24$ \\
\hline \multicolumn{4}{|l|}{ Chest HRCT findings } \\
\hline LAA score & $9.52 \pm 0.76$ & $5.09 \pm 1.16 *$ & $0.00 \pm 0.00 * * *$ \\
\hline Bronchial wall thickening, $\mathrm{n}(\%)$ & $27(25.0)$ & $12(37.5)$ & $15(55.6)^{*}$ \\
\hline
\end{tabular}

Notes: Values are mean \pm standard error of the mean. $* P<0.01$ vs COPD. $* * P<0.01$ vs ACOS.

Abbreviations: COPD, chronic obstructive pulmonary disease; $\mathrm{ACOS}$, asthma-COPD overlap syndrome; asthma $\mathrm{FL}^{+}$, asthma with airflow limitation; $\mathrm{HRCT}$, high-resolution computed tomography; LAA, low attenuation area.

in the COPD group $(229 \pm 29 \mathrm{~mL}[14.90 \% \pm 1.88 \%$ predicted] vs $72 \pm 10 \mathrm{~mL}$ [ $4.54 \% \pm 0.59 \%$ predicted], $P<0.01)$ and the asthma $\mathrm{FL}^{+}$group $(229 \pm 29 \mathrm{~mL}[14.90 \% \pm 1.88 \%$ predicted] vs $153 \pm 21 \mathrm{~mL}$ [ $9.70 \% \pm 1.38 \%$ predicted], $P<0.05$ ). It was also significantly greater in the asthma $\mathrm{FL}^{+}$group than in the COPD group $(153 \pm 21 \mathrm{~mL}[9.70 \% \pm 1.38 \%$ predicted $]$ vs $72 \pm 10 \mathrm{~mL}[4.54 \% \pm 0.59 \%$ predicted], $P<0.01$ ).

Table 3 shows respiratory impedance measured using a multifrequency FOT device (MostGraph- $01^{\circledR}$ ). At the whole-breath, expiratory, and inspiratory phases, R5 and R20 were significantly higher in the asthma $\mathrm{FL}^{+}$group than in the COPD group. In the ACOS group, the values of

Table 2 Pulmonary function of patients with COPD, ACOS, and asthma $\mathrm{FL}^{+}$

\begin{tabular}{|c|c|c|c|}
\hline & $\begin{array}{l}\text { COPD } \\
(n=|| 8)\end{array}$ & $\begin{array}{l}A C O S \\
(n=32)\end{array}$ & $\begin{array}{l}\text { Asthma } \mathrm{FL}^{+} \\
(\mathrm{n}=\mathbf{2 7})\end{array}$ \\
\hline VC, \% predicted & $8.70 \pm 1.70$ & $95.57 \pm 3.05$ & $101.34 \pm 3.07$ \\
\hline FVC, \% predicted & $97.72 \pm 1.88$ & $90.82 \pm 3.26$ & $99.53 \pm 3.55$ \\
\hline $\mathrm{FEV}_{1}$, \% predicted & $69.84 \pm 1.85$ & $63.43 \pm 3.22$ & $76.28 \pm 2.54 *$ \\
\hline $\mathrm{FEV}_{1} / \mathrm{FVC}, \%$ & $56.97 \pm 1.01$ & $55.98 \pm 1.66$ & $61.06 \pm 1.28$ \\
\hline PEFR, \% predicted & $69.67 \pm 2.09$ & $61.08 \pm 3.54$ & $74.40 \pm 3.16 *$ \\
\hline MMF, \% predicted & $25.56 \pm 1.01$ & $23.03 \pm 1.78$ & $27.67 \pm 1.59$ \\
\hline FRC, \% predicted & $100.98 \pm 2.04$ & $104.74 \pm 3.65$ & || $1.30 \pm 6.61$ \\
\hline RV, \% predicted & $137.38 \pm 3.43$ & $148.46 \pm 6.25$ & II $2.05 \pm 4.34 * *, * * *$ \\
\hline TLC, \% predicted & $1 \mid 2.48 \pm 1.40$ & $112.93 \pm 2.57$ & $111.74 \pm 3.12$ \\
\hline DLco, \% predicted & $64.93 \pm 2.15$ & $70.67 \pm 3.68$ & $85.70 \pm 3.19 * * * *$ \\
\hline DLco/VA, \% predicted & $80.5 \mathrm{I} \pm 2.55$ & $85.70 \pm 4.12$ & $118.50 \pm 4.06 * *, * * *$ \\
\hline Delta $\mathrm{N}_{2}, \% \mathrm{~N}_{2} / \mathrm{L}$ & $3.21 \pm 0.20$ & $2.63 \pm 0.35$ & $2.35 \pm 0.24$ \\
\hline CV/VC, \% & $20.4 I \pm 1.28$ & $18.23 \pm 1.95$ & $16.76 \pm 2.12$ \\
\hline
\end{tabular}

Notes: Values are mean \pm standard error of the mean. Delta $N_{2}$, slope of Phase III of the single breath nitrogen washout test. $* * * P<0.0$ I vs COPD. $* * P<0.0$ I. $* P<0.05$ vs ACOS.

Abbreviations: ACOS, asthma-COPD overlap syndrome; asthma $\mathrm{FL}^{+}$, asthma with airflow limitation; VC, vital capacity; FVC, forced vital capacity; $\mathrm{FEV}_{\mathrm{l}}$, forced expiratory volume in I second; PEFR, peak expiratory flow rate; MMF, maximum midexpiratory flow rate; FRC, functional residual capacity; RV, residual volume; TLC, total lung capacity; DLco, diffusing capacity for carbon monoxide; DLco/VA, diffusing capacity of lung for carbon monoxide corrected for alveolar volume; CV/VC, closing volume/vital capacity. these oscillatory parameters ranged between the values of the asthma $\mathrm{FL}^{+}$group and the COPD group; however, the differences between the ACOS group and the other groups were not statistically significant.

\section{Discussion}

This is the first report to compare the pulmonary function, including respiratory impedance, of patients with COPD, ACOS, and asthma $\mathrm{FL}^{+}$. We assessed the differences in the respiratory physiology of patients with these obstructive
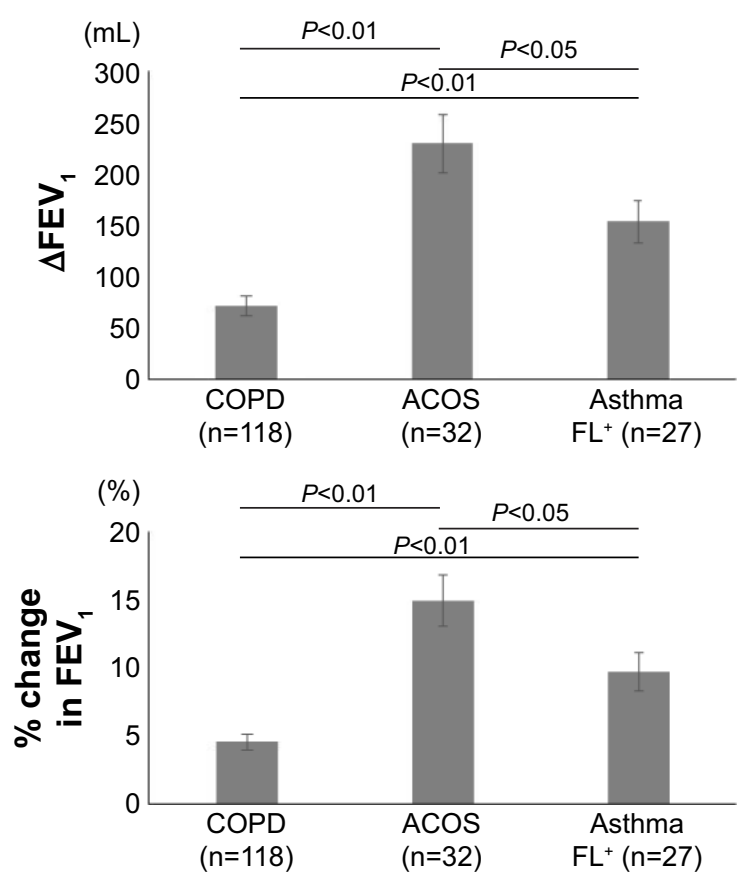

Figure I Response to short-acting $\beta 2$ agonists in patients with COPD, ACOS, and asthma $\mathrm{FL}^{+}$.

Note: Values are mean \pm standard error of the mean.

Abbreviations: ACOS, asthma-COPD overlap syndrome; asthma $\mathrm{FL}^{+}$, asthma with airflow limitation; $\mathrm{FEV}_{1}$, forced expiratory volume in I second; $\triangle \mathrm{FEV}_{1}$, increases in $\mathrm{FEV}_{1}$. 
Table 3 Respiratory impedance in patients with COPD, ACOS, and asthma $\mathrm{FL}^{+}$

\begin{tabular}{|c|c|c|c|}
\hline & $\begin{array}{l}\text { COPD } \\
(n=\mid 18)\end{array}$ & $\begin{array}{l}\text { ACOS } \\
(n=32)\end{array}$ & $\begin{array}{l}\text { Asthma FL } \\
(n=27)\end{array}$ \\
\hline \multicolumn{4}{|l|}{ Whole-breath } \\
\hline $\mathrm{R} 5\left(\mathrm{cmH}_{2} \mathrm{O} / \mathrm{L} / \mathrm{s}\right)$ & $3.4 I \pm 0.14$ & $3.65 \pm 0.22$ & $4.29 \pm 0.30 * *$ \\
\hline $\mathrm{R} 20\left(\mathrm{cmH}_{2} \mathrm{O} / \mathrm{L} / \mathrm{s}\right)$ & $2.68 \pm 0.10$ & $3.03 \pm 0.15$ & $3.50 \pm 0.24 * *$ \\
\hline $\mathrm{R} 5-\mathrm{R} 20\left(\mathrm{cmH}_{2} \mathrm{O} / \mathrm{L} / \mathrm{s}\right)$ & $0.75 \pm 0.06$ & $0.63 \pm 0.11$ & $0.79 \pm 0.17$ \\
\hline $\mathrm{X} 5\left(\mathrm{cmH}_{2} \mathrm{O} / \mathrm{L} / \mathrm{s}\right)$ & $-1.32 \pm 0.12$ & $-1.5 I \pm 0.23$ & $-1.39 \pm 0.20$ \\
\hline Fres $(\mathrm{Hz})$ & $|3.2| \pm 0.52$ & $13.66 \pm 0.96$ & $14.18 \pm 1.00$ \\
\hline $\mathrm{ALX}\left(\mathrm{cmH}_{2} \mathrm{O} / \mathrm{L} / \mathrm{s} \mathrm{Hz}\right)$ & $10.15 \pm 1.27$ & $10.75 \pm 2.08$ & $10.34 \pm 1.95$ \\
\hline \multicolumn{4}{|l|}{ Expiratory phase } \\
\hline $\mathrm{R} 5\left(\mathrm{cmH}_{2} \mathrm{O} / \mathrm{L} / \mathrm{s}\right)$ & $3.75 \pm 0.17$ & $3.98 \pm 0.25$ & $4.81 \pm 0.34 * *$ \\
\hline $\mathrm{R} 20\left(\mathrm{cmH}_{2} \mathrm{O} / \mathrm{L} / \mathrm{s}\right)$ & $2.80 \pm 0.11$ & $3.18 \pm 0.16$ & $3.69 \pm 0.30 * *$ \\
\hline $\mathrm{R} 5-\mathrm{R} 20\left(\mathrm{cmH}_{2} \mathrm{O} / \mathrm{L} / \mathrm{s}\right)$ & $0.95 \pm 0.07$ & $0.80 \pm 0.14$ & $1.03 \pm 0.18$ \\
\hline $\mathrm{X} 5\left(\mathrm{cmH}_{2} \mathrm{O} / \mathrm{L} / \mathrm{s}\right)$ & $-1.78 \pm 0.20$ & $-1.91 \pm 0.34$ & $-1.67 \pm 0.28$ \\
\hline Fres $(\mathrm{Hz})$ & $|4.8| \pm 0.65$ & $\mid 5.19 \pm 1.21$ & $15.83 \pm 1.20$ \\
\hline $\mathrm{ALX}\left(\mathrm{cmH}_{2} \mathrm{O} / \mathrm{L} / \mathrm{s} \mathrm{Hz}\right)$ & $15.04 \pm 2.24$ & $14.94 \pm 3.19$ & $13.60 \pm 2.86$ \\
\hline \multicolumn{4}{|l|}{ Inspiratory phase } \\
\hline $\mathrm{R} 5\left(\mathrm{cmH}_{2} \mathrm{O} / \mathrm{L} / \mathrm{s}\right)$ & $3.06 \pm 0.13$ & $3.33 \pm 0.21$ & $3.76 \pm 0.28 *$ \\
\hline $\mathrm{R} 20\left(\mathrm{cmH}_{2} \mathrm{O} / \mathrm{L} / \mathrm{s}\right)$ & $2.54 \pm 0.10$ & $2.87 \pm 0.15$ & $3.10 \pm 0.24 * *$ \\
\hline $\mathrm{R} 5-\mathrm{R} 20\left(\mathrm{cmH}_{2} \mathrm{O} / \mathrm{L} / \mathrm{s}\right)$ & $0.52 \pm 0.06$ & $0.46 \pm 0.10$ & $0.55 \pm 0.17$ \\
\hline $\mathrm{X} 5\left(\mathrm{cmH}_{2} \mathrm{O} / \mathrm{L} / \mathrm{s}\right)$ & $-0.84 \pm 0.06$ & $-1.11 \pm 0.15$ & $-1.11 \pm 0.14$ \\
\hline Fres $(\mathrm{Hz})$ & $\mid \mathrm{I} .6 \mathrm{I} \pm 0.43$ & $12.13 \pm 0.76$ & $12.52 \pm 0.87$ \\
\hline $\mathrm{ALX}\left(\mathrm{cmH}_{2} \mathrm{O} / \mathrm{L} / \mathrm{s} \mathrm{Hz}\right)$ & $5.13 \pm 0.5 \mid$ & $6.53 \pm 1.14$ & $7.08 \pm 1.26$ \\
\hline \multicolumn{4}{|c|}{ Differences between inspiratory and expiratory phases } \\
\hline $\mathrm{R} 5\left(\mathrm{cmH}_{2} \mathrm{O} / \mathrm{L} / \mathrm{s}\right)$ & $-0.69 \pm 0.11$ & $-0.65 \pm 0.11$ & $-1.05 \pm 0.20 *$ \\
\hline $\mathrm{R} 20\left(\mathrm{cmH}_{2} \mathrm{O} / \mathrm{L} / \mathrm{s}\right)$ & $-0.26 \pm 0.07$ & $-0.3 \mathrm{I} \pm 0.07$ & $-0.59 \pm 0.13^{*}$ \\
\hline $\mathrm{R} 5-\mathrm{R} 20\left(\mathrm{cmH}_{2} \mathrm{O} / \mathrm{L} / \mathrm{s}\right)$ & $-0.43 \pm 0.06$ & $-0.34 \pm 0.07$ & $-0.47 \pm 0.10$ \\
\hline $\mathrm{X} 5\left(\mathrm{cmH}_{2} \mathrm{O} / \mathrm{L} / \mathrm{s}\right)$ & $0.95 \pm 0.17$ & $0.80 \pm 0.24$ & $0.55 \pm 0.21$ \\
\hline Fres $(\mathrm{Hz})$ & $-3.19 \pm 0.41$ & $-3.06 \pm 0.65$ & $-3.32 \pm 0.64$ \\
\hline $\mathrm{ALX}\left(\mathrm{cmH}_{2} \mathrm{O} / \mathrm{L} / \mathrm{s} \mathrm{Hz}\right)$ & $-9.78 \pm 2.01$ & $-8.42 \pm 2.38$ & $-6.5 I \pm 2.08$ \\
\hline
\end{tabular}

Notes: Values are mean \pm standard error of the mean. $* * P<0.01$. $* P<0.05$ vs $C O P D$ Abbreviations: ACOS, asthma and COPD overlap syndrome; asthma $\mathrm{FL}^{+}$, asthma with airflow limitation; R5 and R20, respiratory resistances at $5 \mathrm{~Hz}$ and $20 \mathrm{~Hz}$ frequencies; $X 5$, respiratory reactance at $5 \mathrm{~Hz}$ frequencies; Fres, resonant frequency; $A L X$, low-frequency reactance area.

pulmonary diseases, which are commonly encountered chronic lung diseases in the clinical setting. We showed that there were significant differences in several parameters of pulmonary function tests between the COPD group and the asthma $\mathrm{FL}^{+}$group and between the ACOS group and the asthma $\mathrm{FL}^{+}$group. There were significant differences among the three groups in the reversibility of airflow limitation in response to short-acting $\beta_{2}$-agonists. R5 and R20, which are oscillatory parameters of respiratory resistance, in both inspiratory and expiratory phases were significantly greater in the asthma $\mathrm{FL}^{+}$group than in the COPD group.

The FOT is theoretically sensitive to peripheral airway function ${ }^{29,30}$ and is easy to administer because it is an effortindependent method of evaluating lung mechanics. The FOT parameters of resistance (Rrs) and reactance (Xrs) are parameters of the airway caliber and of the elastic properties of the respiratory system, respectively, and reflect the properties of both small and large airways. In patients with pulmonary obstructive diseases, the oscillatory flow resistance of the respiratory system tends to increase with the degree of airway obstruction, resulting in an increase in Rrs and negative values in Xrs. Xrs is sensitive and specific to the presence of expiratory flow limitation in patients with $\mathrm{COPD}^{31}$ and to change during the recovery from acute exacerbations of COPD. ${ }^{32}$ The Rrs increased, and Xrs fell to a more negative level in patients with both COPD and asthma in a severity-dependent fashion, regardless of respiratory phase. ${ }^{14-16}$ Mori et al ${ }^{17}$ reported that R5, which indicates total airway resistance, is significantly correlated with $\mathrm{FEV}_{1}$, and that it is significantly higher in patients with COPD than in controls, but not than in patients with asthma. Kanda et $\mathrm{a}^{18}$ reported that $\mathrm{R} 5$ was significantly higher in both patients with COPD and patients with asthma than in healthy never-smokers, and that R20 was significantly higher in patients with asthma than in patients with COPD and healthy never-smokers. We found that both R5 and R20 were significantly higher in patients with asthma $\mathrm{FL}^{+}$than in patients with COPD, regardless of respiratory phase, and more than half of the patients with asthma $\mathrm{FL}^{+}$ (55.6\%) showed BWT on chest HRCT. Our findings suggest that the asthma $\mathrm{FL}^{+}$group included patients with more severe asthma, which involved greater degree of airway remodeling. Indeed, previous studies have revealed that patients with more severe asthma had greater airway wall thickening on chest HRCT than those with mild asthma. ${ }^{33,34}$ On the other hand, although the LAA and airway wall thickening can be observed on the chest HRCT images of many patients with COPD, there are individuals with similar degrees of airflow limitation whose abnormalities appeared to be predominantly related to airway remodeling or whose abnormalities appeared to be predominantly related to a loss of lung parenchyma. ${ }^{33}$ As a consequence of this heterogeneity in COPD, the mean value of the parameters of airway resistance (R5 and R20) may have been lower in patients with COPD than in patients with asthma $\mathrm{FL}^{+}$in the present study.

We found that there were no significant differences in delta $\mathrm{N}_{2}, \mathrm{X} 5$, Fres, and ALX among patients with COPD, ACOS, and asthma $\mathrm{FL}^{+}$. Delta $\mathrm{N}_{2}$ is the preferred parameter, which reflects ventilation heterogeneity, and it increases in a severity-dependent manner in patients with COPD..$^{35}$ X5, Fres, and ALX are significantly correlated with FEV and delta $\mathrm{N}_{2}$ in patients with asthma, ${ }^{24}$ and Fres is significantly correlated with $\mathrm{FEV}_{1}$ and delta $\mathrm{N}_{2}$ in patients with COPD. ${ }^{17,36}$ These findings suggest that ventilation heterogeneity exists in patients with COPD, ACOS, and 
asthma $\mathrm{FL}^{+}$. Furthermore, there was no significant difference in within-breath changes of X5, which suggests the easy collapsibility of small airways during the expiration of the tidal breath, among patients with COPD, ACOS, and asthma $\mathrm{FL}^{+}$. Although previous studies have reported that within-breath changes of X 5 discriminated between patients with COPD and asthma, ${ }^{17,18}$ this may not be applicable to patients with asthma $\mathrm{FL}^{+}$.

We found that there were significant differences in the reversibility of airflow limitation in response to shortacting $\beta_{2}$-agonists among patients with COPD, ACOS, and asthma $\mathrm{FL}^{+}$, and the reversibility of airflow limitation was the greatest in patients with ACOS, whereas the prevalence of BWT on chest HRCT tended to be lower in patients with ACOS than in patients with asthma $\mathrm{FL}^{+}$. These findings suggest that patients with ACOS have a lower degree of airway remodeling due to asthma than patients with asthma $\mathrm{FL}^{+}$. Nakano et $\mathrm{al}^{33}$ reported that the airway wall area on chest HRCT increased without a decrease in the luminal area in patients with asthma, whereas the airway luminal area decreased and airway wall area increased in patients with COPD. This different pattern of remodeling may reflect fundamental differences in the inflammatory processes in COPD and asthma and could influence the reversibility of airflow limitation, although the degree of reversibility of airflow limitation in response to bronchodilators in patients with COPD has never been shown to add to the differential diagnosis with asthma. ${ }^{1}$

There were several limitations in the present study. First, this was a single-center, uncontrolled-design retrospective study with a lack of statistical power due to the small sample size of the asthma $\mathrm{FL}^{+}$group $(\mathrm{n}=27)$. Further prospective studies with larger study populations are required to confirm these results. Second, the assessment of emphysema on chest HRCT was performed according to a visual scoring method, rather than the software-based quantification of the degree of emphysema and BWT. However, the reproducibility of visual scoring was demonstrated in our previous report. ${ }^{27}$ Third, the definition of ACOS was based on a retrospective evaluation of asthma-related symptoms. It is difficult to clinically differentiate between COPD and ACOS in some patients, because asthma-related symptoms may not only be specific for asthma but may also characterize COPD. Fourth, generalizability is a potential problem in the present study. Shinshu University Hospital, which was the site of patient recruitment, is a major hospital and may have more older patients with high disease severity compared with other general hospitals, which results in a potential selection bias.

\section{Conclusion}

Although persistent airflow limitation occurs in patients with COPD, ACOS, and asthma $\mathrm{FL}^{+}$, they may have distinct characteristics of the respiratory physiology and different responsiveness to bronchodilators.

\section{Disclosure}

The authors report no conflicts of interest in this work.

\section{References}

1. Global Initiative for Chronic Obstructive Lung Disease [homepage on the Internet]. Global Strategy for the Diagnosis, Management, and Prevention of Chronic Obstructive Pulmonary Disease. NHLBI/WHO Workshop Report. Bethesda: National Heart, Lung and Blood Institute; 2001 [Updated 2015]. Available from: http://www.goldcopd.com. Accessed January 31, 2016.

2. Vonk JM, Jongepier H, Panhuysen CI, Schouten JP, Bleecker ER, Postma DS. Risk factors associated with the presence of irreversible airflow limitation and reduced transfer coefficient in patients with asthma after 26 years of follow up. Thorax. 2003;58(4):322-327.

3. Jeffery PK. Remodeling and inflammation of bronchi in asthma and chronic obstructive pulmonary disease. Proc Am Thorac Soc. 2004;1(3):176-183.

4. GINA [homepage on the Internet]. Global Strategy for Asthma Management and Prevention, Global Initiative for Asthma (GINA) [Updated 2015]. Available from: http://www.ginasthma.org/. Accessed January 31, 2016.

5. Silva GE, Sherrill DL, Guerra S, Barbee RA. Asthma as a risk factor for COPD in a longitudinal study. Chest. 2004;126(1):59-65.

6. Tzortzaki EG, Proklou A, Siafakas NM. Asthma in the elderly: can we distinguish it from COPD? J Allergy (Cairo). 2011;2011:843543.

7. Diaz-Guzman E, Mannino DM. Airway obstructive diseases in older adults: from detection to treatment. J Allergy Clin Immunol. 2010; 126(4):702-709.

8. Gibson PG, McDonald VM, Marks GB. Asthma in older adults. Lancet. 2010;376(9743):803-813.

9. Carolan BJ, Sutherland ER. Clinical phenotypes of chronic obstructive pulmonary disease and asthma: recent advances. J Allergy Clin Immunol. 2013;131(3):627-634.

10. Kim SR, Rhee YK. Overlap between asthma and COPD: where the two diseases converge. Allergy Asthma Immunol Res. 2010;2(4):209-214.

11. Louie S, Zeki AA, Schivo M, et al. The asthma-chronic obstructive pulmonary disease overlap syndrome: pharmacotherapeutic considerations. Expert Rev Clin Pharmacol. 2013;6:197-219.

12. Nakawah MO, Hawkins C, Barbandi F. Asthma, chronic obstructive pulmonary disease (COPD), and the overlap syndrome. J Am Board Fam Med. 2013;26(4):470-477.

13. GINA and GOLD [homepage on the Internet]. Diagnosis of Diseases of Chronic Airflow Limitation: Asthma, COPD and Asthma-COPD Overlap Syndrome (ACOS) [updated 2015]. Available from: http:// www.ginasthma.org/. Accessed: January 31, 2015.

14. Ohishi J, Kurosawa H, Ogawa H, Irokawa T, Hida W, Kohzuki M. Application of impulse oscillometry for within-breath analysis in patients with chronic obstructive pulmonary disease: pilot study. $B M J$ Open. 2011;1(2):e00184.

15. Grimby G, Takishima T, Graham W, Macklem P, Mead J. Frequency dependence of flow resistance in patients with obstructive lung disease. J Clin Invest. 1968;47(6):1455-1465.

16. Cavalcanti JV, Lopes AJ, Jansen JM, Melo PL. Detection of changes in respiratory mechanics due to increasing degrees of airway obstruction in asthma by the forced oscillation technique. Respir Med. 2006; 100(12):2207-2219. 
17. Mori K, Shirai T, Mikamo M, et al. Colored 3-dimensional analyses of respiratory resistance and reactance in COPD and asthma. COPD. 2011;8(6):456-463.

18. Kanda S, Fujimoto K, Komatsu Y, et al. Evaluation of respiratory impedance in asthma and COPD by an impulse oscillation system. Intern Med. 2010;49(1):23-30.

19. Kitaguchi Y, Komatsu Y, Fujimoto K, Hanaoka M, Kubo K. Sputum eosinophilia can predict responsiveness to inhaled corticosteroid treatment in patients with overlap syndrome of COPD and asthma. Int $J$ Chron Obstruct Pulmon Dis. 2012;7:283-289.

20. Japanese Society of Chest Disease. Standards of pulmonary function tests for Japanese. Jpn J Respir Dis. 1993;31:421-427.

21. Nishida O, Kambe M, Sewake N, Takano M, Kawane H. Pulmonary function in healthy subjects and its prediction: 5. Pulmonary diffusing capacity in adults. Jpn J Clin Pathol. 1976;24(11):941-947.

22. Boren HG, Kory RC, Syner JC, Callahan R. The Veterans AdministrationArmy cooperative study of pulmonary function. 2. The lung volume and its subdivisions in normal men. Am J Med. 1966;41:96-101.

23. Mori K, Shirai T, Mikamo M, et al. Respiratory mechanics measured by forced oscillation technique in combined pulmonary fibrosis and emphysema. Respir Physiol Neurobiol. 2013;185(2):235-240.

24. Shirai T, Mori K, Mikamo M, et al. Respiratory mechanics and peripheral airway inflammation and dysfunction in asthma. Clin Exp Allergy 2013;43(5):521-526.

25. Oostveen E, MacLeod D, Lorino H, et al. ERS Task Force on Respiratory Impedance Measurements. The forced oscillation technique in clinical practice: methodology, recommendations and future developments. Eur Respir J. 2003;22(6):1026-1041.

26. Kitaguchi Y, Fujimoto K, Kubo K, Honda T. Characteristics of COPD phenotypes classified according to the findings of HRCT. Respir Med. 2006;100(10):1742-1752.
27. Fujimoto K, Kitaguchi Y, Kubo K, Honda T. Clinical analysis of chronic obstructive pulmonary disease phenotypes classified using highresolution computed tomography. Respirology. 2006;11(6):731-740.

28. Goddard PR, Nicholson EM, Laszlo G, Watt I. Computed tomography in pulmonary emphysema. Clin Radiol. 1982;33(4):379-387.

29. Lutchen KR, Gillis H. Relationship between heterogeneous changes in airway morphometry and lung resistance and elastance. J Appl Physiol (1985). 1997;83(4):1192-1201.

30. Thorpe CW, Bates JH. Effect of stochastic heterogeneity on lung impedance during acute bronchoconstriction: a model analysis. $J \mathrm{Appl}$ Physiol. 1985;1997(82):1616-1625.

31. Dellacà RL, Santus $\mathrm{P}$, Aliverti A, et al. Detection of expiratory flow limitation in COPD using the forced oscillation technique. Eur Respir J. 2004;23(2):232-240.

32. Johnson MK, Birch M, Carter R, Kinsella J, Stevenson RD. Measurement of physiological recovery from exacerbation of chronic obstructive pulmonary disease using within-breath forced oscillometry. Thorax. 2007;62(4):299-306.

33. Nakano Y, Müller NL, King GG, et al. Quantitative assessment of airway remodeling using high-resolution CT. Chest. 2002; 122(6 suppl):271S-275S.

34. Awadh N, Müller NL, Park CS, Abboud RT, FitzGerald JM. Airway wall thickness in patients with near fatal asthma and control groups: assessment with high resolution computed tomographic scanning. Thorax. 1998;53(4):248-253.

35. Gennimata SA, Palamidas A, Karakontaki F, et al. Pathophysiology of evolution of small airways disease to overt COPD. COPD. 2010;7(4): 269-275.

36. Mikamo M, Shirai T, Mori K, et al. Predictors of phase III slope of nitrogen single-breath washout in COPD. Respir Physiol Neurobiol. 2013;189(1):42-46.
International Journal of COPD

\section{Publish your work in this journal}

The International Journal of COPD is an international, peer-reviewed journal of therapeutics and pharmacology focusing on concise rapid reporting of clinical studies and reviews in COPD. Special focus is given to the pathophysiological processes underlying the disease, intervention programs, patient focused education, and self management protocols.

\section{Dovepress}

This journal is indexed on PubMed Central, MedLine and CAS. The manuscript management system is completely online and includes a very quick and fair peer-review system, which is all easy to use. Visit http://www.dovepress.com/testimonials.php to read real quotes from published authors. 